\title{
Previsão de demanda de minério de ferro da Empresa Vale S.A. no período de 2010 a 2015
}

\section{Iron ore demand forecasting of the Company Vale S.A. in the 2010 to 2015 period}

\author{
Rodrigo Salvador \\ Universidade Tecnológica Federal do Paraná - UTFPR - Ponta Grossa - Brasil \\ salvador.rodrigors@gmail.com \\ Jessica Yasmin Saito Pozzobon \\ Universidade Tecnológica Federal do Paraná - UTFPR - Ponta Grossa - Brasil \\ je.pozzobon@gmail.com \\ Mariana de Almeida Ribeiro \\ Universidade Tecnológica Federal do Paraná - UTFPR - Ponta Grossa - Brasil \\ marianaalmeida5@hotmail.com \\ Jessyca Moraes \\ Universidade Tecnológica Federal do Paraná - UTFPR - Ponta Grossa - Brasil \\ jessy1201@gmail.com \\ Claudia Tania Picinin \\ Universidade Tecnológica Federal do Paraná - UTFPR - Ponta Grossa - Brasil \\ claudiapicinin@utfpr.edu.br
}

\begin{abstract}
Resumo
O presente trabalho tem como objetivo realizar a previsão de demanda do minério de ferro da empresa Vale S.A. no período de 2010 a 2015. Para tanto utilizou-se do método de regressão linear múltipla, realizado com auxílio do software IBM SPSS Statistics 23. Obtendo como resultado a equação da previsão de demanda do minério de ferro dadas as variáveis preditivas produção mundial de aço, preço do minério de ferro e movimentação portuária minério de ferro, sendo que apenas o coeficiente atribuído à variável preço do minério de ferro é não significativo ao nível de confiança de $95 \%$. Essa previsão auxilia outras empresas do mesmo ramo a analisarem a previsão de demanda da empresa Vale S.A para assim adaptarem seu desempenho.
\end{abstract}

Palavras-chave: previsão de demanda, minério de ferro, regressão linear múltipla.

\section{Abstract}

This paper aims to conduct the demand forecasting for iron ore from Vale S.A. in the period of 2010 to 2015. For this purpose, it was used the multiple linear regression method, performed with the help of IBM SPSS Statistics 23 software. The results were found through the use of the equation of iron ore demand forecasting given the predictive variables such as world steel production, the price of iron ore and port iron ore handling, and only the coefficient assigned to the variable price of iron ore is not significant at the 
95\%. The prediction helps other companies in the same industry to examine the demand forecasting of the company Vale S.A. to adapt their performance.

Keywords: demand forecasting, iron ore, multiple linear regression.

\section{Introdução}

A previsão de demanda é considerada um desafio, já que muitas vezes os padrões de variação são imprevisíveis, dificultando assim a previsão. Em contrapartida, quando se consegue realizar a previsão de demanda, essa facilita e auxilia na de tomada decisão empresarial, gerando vantagem competitiva para a organização, uma vez que é a base para o planejamento organizacional (MANCUZO, 2003). Para a realização da previsão de demanda a empresa se utiliza de softwares, os quais fornecem informações que permitem o gerenciamento da cadeia de suprimentos e demanda (SLACK et al., 2007).

Para Xuan e Yue (2016) para se obter a máxima precisão na previsão demandada de um determinado produto parte da quantificação de todas as variáveis envolvidas no processo, pois assim, o erro é minimizado durante o processo de previsão da demanda. Wang et al. (2015) ressalta que quanto maior a precisão nos cálculos de demanda menores são os desperdícios e a nocividade ao meio-ambiente. Lauinger et al. (2016) complementa afirmando que a previsão facilita a tomada de decisão, pois se já havia uma previsão, mesmo que englobe um erro, as intervenções futuras são agilizadas.

A previsão de demanda do minério de ferro é relevante uma vez que as jazidas de minério de ferro que é o foco do presente trabalho não apresentam uma distribuição mundial uniforme e são altamente dependentes da demanda de aço, a qual tende a crescer a uma taxa de 4,2\% até o ano de 2017 (CARVALHO, 2013).

As jazidas de minério de ferro estão concentradas principalmente na Austrália que ocupa a primeira posição com relação à reserva desse minério. A segunda posição do ranking é ocupa pelo Brasil, seguido da Rússia e da China (CARVALHO, 2013). Com relação à produção do minério de ferro o Brasil ocupa a terceira posição, perdendo apenas para a China e a Austrália (IBRAM, 2012).

Vários estudos sobre a demanda de ferro e aço na China empregam vários métodos. A abordagem mais comum é a análise econométrica que respeita a demanda de aço, ou ferro, em função do produto interno bruto (PIB) ou PIB per capita - avalia o PIB em função da população (XUAN; YUE, 2016).

No Brasil os principais estados produtores do minério são: Minas Gerais que apresenta $67 \%$ da produção do país e o Pará com $29,3 \%$. Segundo dados do IBRAM (Instituto Brasileiro de Mineração) até final de 2015 o mercado mundial possuía grande dependência por minério de ferro australiano e brasileiro.

O presente trabalho tem como objetivo realizar a previsão de demanda do minério de ferro da empresa Vale S.A. no período de 2010 a 2015. A empresa é uma mineradora fundada em 1942 localizada na Floresta Municipal do Carajás-Pará, com foco principal na extração de minérios de ferro e níquel no local (VALE, 2016a). Esta previsão ocorrerá através do método de previsão por regressão linear múltipla, sendo que as variáveis independentes que influenciam na demanda do minério de ferro foram definidas a partir das informações disponibilizadas pela empresa e da análise dos fatores que influenciam a previsão. Para este caso foram definidas três variáveis independentes, sendo estas: movimentação portuária do minério de ferro, preço do minério de ferro e produção de aço. Segundo dados do CARVALHO (2013) o mercado de minério de ferro é altamente influenciado pela demanda do aço, sendo que a oferta do minério de ferro depende da sua distribuição geográfica.

A escolha do minério de ferro para se realizar a previsão se deu pelo fato de ser um produto com alta demanda mundial (CARVALHO, 2013), além da Vale S.A estar entre 
as principais empresas produtoras do minério de ferro, segundo Carvalho (2013). A partir desse estudo será possível verificar a influência das variáveis independentes na demanda do minério de ferro, essa previsão auxilia outras empresas do mesmo ramo a analisarem a previsão de demanda da empresa Vale S.A para assim adaptarem seu desempenho.

\section{Previsão de demanda}

A demanda é definida como a quantidade de bens e serviços que podem ser compradas por um determinado preço, e para realizar a previsão de demanda é possível à utilização de técnicas tais como métodos informais e métodos quantitativos (SHARMA; SHARMA, 2015).

Para Xuan e Yue (2016) a demanda deve usar um modelo matemático que envolve a análise logarítmica de decomposição da média por meio da divisão de picos de consumo, desse modo é possível ajustar a taxa de utilização do material em estudo. Quando previsto todos os números as possibilidades de erros diminuem.

A previsão de demanda pode ser considerada um fator inicial a ser utilizado no momento de planejar a realização de diversas atividades dentro de uma organização. Esta atividade pode ser realizada em diversos locais, tais como na área de vendas, planejamento e gerenciamento da produção, entre outros. Porém, a partir do momento que se encontra um alto erro na previsão de demanda, verifica-se que o planejamento das atividades, consequentemente, será realizado com maiores dificuldades, as quais podem acarretar em perdas financeiras (MIRANDA et al., 2011).

Wang et al. (2015) assume que a previsão da demanda está diretamente ligada a uma economia saudável, pois pode evitar desperdícios contribuindo para manutenção ambiental, se economiza recursos não proporciona o gasto desnecessário destes.

Além disso, segundo Martins e Laugeni (2005), a previsão da demanda é um processo para determinar dados futuros, gerar a demanda baseada em modelos estatísticos, matemáticos ou ainda em modelos subjetivos apoiados em um processo de trabalho, clara e previamente definido. O lead time, que é o tempo necessário para um produto percorrer do início até o final todas as etapas dentro de um processo, é a razão principal para se realizar um planejamento e uma previsão. Se o lead time é curto, não existe a necessidade de planejamento, porém, se o lead time é longo, é necessário realizar um planejamento. Em cada uma dessas situações, a previsão é necessária para determinar quando um evento ocorrerá para que ações apropriadas possam ser tomadas (MA; ZHU; WANG, 2013). A realização de uma previsão é relevante para uma eficiência e eficácia no planejamento produtivo (MAKRIDAKIS; WHEELWRIGHT; HYNDMAN, 1998).

A organização necessita ter conhecimento e habilidades para cobrir pelo menos quatro áreas, das quais: identificação e definição dos problemas de previsão; aplicação de uma significativa quantidade de métodos de previsão; procedimentos para selecionar os métodos apropriados para uma situação específica e suporte organizacional para aplicar e utilizar formalmente os métodos de previsão (MAKRIDAKIS; WHEELWRIGHT; HYNDMAN, 1998).

A previsão de demanda pode ser realizada por meio da utilização de métodos quantitativos, qualitativos ou ambos. Os métodos quantitativos normalmente analisam uma série de dados, enquanto os qualitativos buscam a opinião de especialistas (PELLEGRINI; FOGLIATTO, 2001). A escolha do método a ser utilizado depende de alguns fatores, tais como a necessidade de análise de um horizonte de tempo (curto, médio ou longo prazo); a quantidade de dados disponibilizados; a precisão adequada, e a disponibilidade de profissionais qualificados (SOUSA et al., 2014). Ainda de acordo com Sousa et al., (2014) para realizar uma previsão de demanda adequada, pode-se seguir cinco passos: definir o objetivo do modelo, coletar e analisar os dados, selecionar a técnica de previsão, obtenção das previsões e monitoramento e atualização do modelo. 
Em uma indústria, tal como a de minério de ferro, a previsão de demanda necessita de análise em longos períodos, uma vez que na realização da projeção de mercado observa-se uma grande variedade na economia e nos cenários tecnológicos. Ademais, segundo Sharma e Sharma (2015), o mercado de minérios apresenta uma grande complexidade na relação fornecedor-demanda-preço, e uma falta de fornecimento de dados confiáveis para a realização da previsão de demanda.

\section{Métodos}

Para a realização da pesquisa e aplicação do método de regressão o corpus documental foi coletado a partir de fontes secundárias a respeito das variáveis analisadas, sendo elas: a produção mundial de aço (WORLDSTEEL, 2015) a demanda de minério de ferro (VALE, 2016a), o preço praticado do minério de ferro pela empresa Vale S.A. e a movimentação portuária (ANTAQ, 2016) de minério de ferro no Brasil.

Foram coletados os dados das variáveis citadas para os anos de 2010 a 2015 . 0 período mencionado foi dado em função dos dados de movimentação portuária estarem disponíveis somente a partir do ano de 2010. Ressalta-se que é recomendável que seja utilizada uma série histórica com horizonte de tempo maior para a realização da análise de regressão. Neste caso, como uma das variáveis teve dados disponíveis apenas em relação a um período restrito de tempo (2010-2015), este mesmo período foi aplicado também às outras três variáveis.

Outra restrição temporal foi a disponibilidade dos dados de demanda e de preço do minério de ferro, constantes nos relatórios da empresa Vale S.A. A publicação dos relatórios é trimestral, sendo os dados disponibilizados também com base neste período de tempo, não havendo detalhamento dos dados para cada mês, apenas para o trimestre como um todo. Deste modo, os dados da produção mundial de aço e da movimentação portuária de minério de ferro foram também adaptados para tal abordagem temporal.

Para a obtenção dos dados da venda de minério de ferro e do preço do minério de ferro, como já citado, foram utilizados os relatórios trimestrais da empresa Vale (2016a), disponibilizados no próprio site da empresa. De fácil acesso, as planilhas possuem um menu que direciona o leitor à área desejada. Os volumes de venda foram obtidos acessando o menu "Volume Vendido - Minérios e Metais" e os preços acessando o menu "Preços Médios"; para ambos foi realizada leitura direta dos valores para minério de ferro. O processo se repetiu para todos os trimestres com siderados neste estudo.

Os dados da produção mundial de aço foram obtidos a partir dos relatórios anuais de produção de aço disponibilizados pela instituição WorldSteel (2015). São disponibilizados os valores da produção mensal de aço bruto em 66 países, que segundo a organização corresponde a aproximadamente $98,6 \%$ da produção mundial total de aço bruto. Como os dados são mensais e considerou-se valores trimestrais no presente estudo, foi realizada média aritmética simples para os meses de janeiro, fevereiro e março para o primeiro trimestre (T1), abril, maio e junho para o segundo trimestre (T2), julho, agosto e setembro para o terceiro trimestre (T3) e outubro, novembro e dezembro para o quarto trimestre (T4) de cada ano (2010, 2011, 2012, 2013, 2014 e 2015).

Para coleta de dados a respeito da movimentação portuária de minério de ferro, foi utilizada a ferramenta estatística disponível no site da Agência Nacional de Transportes Aquaviários (ANTAQ, 2016). No site da instituição, a partir da página inicial é possível acessar o menu "estatísticas" e em seguida o submenu "anuários estatísticos", a partir de onde é possível obter informações de quaisquer tipos cargas em quaisquer tipos de navegação por ela regulamentados. Para o presente estudo os dados da movimentação de minério de ferro foram obtidos, a partir dos comandos anteriormente mencionados, selecionando-se transporte via longo de curso. Então selecionou-se cada um dos anos considerados neste estudo $(2010,2011,2012,2013,2014$ e 2015) a partir do menu 
provido pelo próprio site, e em seguida o trimestre desejado para o ano escolhido. Então para filtros de carga foi escolhido "minérios escórias e cinzas". É fornecido o valor da carga para o período selecionado em toneladas transportadas. O procedimento foi repetido para cada um dos 4 trimestres de cada um dos anos considerados neste estudo.

Após o término da coleta de dados procedeu-se a análise dos dados obtidos. Para a realização de regressão múltipla seguiu-se os passos abordados a seguir utilizando o software estatístico IBM Statistical Package for the Social Sciences (SPSS) versão 23.

Cada conjunto de dados coletados foi disposto graficamente por meio da utilização do gráfico boxplot para observação de outliers. Foi observada total ausência dos mesmos, portanto prosseguiu-se com o tratamento dos dados.

Foi realizada, na sequência, análise de normalidade para todos os conjuntos de dados por meio do teste da análise de assimetria e curtose, sendo os dados considerados normais para valores de assimetria e curtose menores ou iguais a 1,5 em módulo (DANCEY; REIDY, 2004).

Após a confirmação de que todos os conjuntos de dados apresentavam distribuição normal foi aplicado o teste de correlação de Pearson para avaliar tendência de variação conjunta entre os mesmos, par a par, e para a verificação da existência de multicolinearidade entre as variáveis independentes.

$\mathrm{Em}$ posse das afirmações anteriores foi realizado o teste de regressão linear múltipla por meio do método Enter tendo como variáveis independentes a demanda mundial de aço, a movimentação portuária e o preço do minério de ferro; e como variável dependente a demanda de minério de ferro.

\section{Resultados e Discussões}

Para que fosse possível realizar a previsão da demanda pelo método de Regressão Linear Múltipla foram aplicados os passos descritos na seção 3. Os conjuntos de dados utilizados para cada análise são apresentados na Tabela 1.

Tabela 1: Conjuntos de dados utilizados para a realização da previsão da demanda

\begin{tabular}{|c|c|c|c|c|}
\hline Trimestre & $\begin{array}{c}\text { Produção mundial } \\
\text { de aço } \\
\text { (milhões ton.m) }\end{array}$ & $\begin{array}{c}\text { Demanda } \\
\text { minério de ferrob } \\
\text { (mil ton.m) }\end{array}$ & $\begin{array}{l}\text { Preço minério } \\
\text { de ferrob } \\
\text { (U\$\$/ton.m) }\end{array}$ & $\begin{array}{l}\text { Movimentação } \\
\text { portuária de minério de } \\
\text { ferro no Brasil (mil ton) }\end{array}$ \\
\hline $1 \mathrm{~T} 10$ & $113,655.00$ & $57,875.00$ & 64.76 & $60,029.00$ \\
\hline $2 \mathrm{~T} 10$ & $121,301.67$ & $59,124.00$ & 91.93 & $72,629.00$ \\
\hline $3 T 10$ & $113,548.67$ & $68,043.00$ & 128.21 & $82,848.00$ \\
\hline $4 \mathrm{~T} 10$ & $115,404.33$ & $69,860.00$ & 121.34 & $86,480.00$ \\
\hline $1 \mathrm{~T} 11$ & $125,429.67$ & $57,745.00$ & 126.19 & $72,523.00$ \\
\hline $2 \mathrm{~T} 11$ & $128,113.00$ & $62,644.00$ & 145.30 & $78,016.00$ \\
\hline 3T11 & $124,833.00$ & $67,007.81$ & 151.26 & $87,828.00$ \\
\hline $4 \mathrm{~T} 11$ & $118,653.00$ & $69,890.26$ & 121.38 & $89,642.00$ \\
\hline $1 \mathrm{~T} 12$ & $125,814.00$ & $54,793.00$ & 109.26 & $71,659.00$ \\
\hline $2 \mathrm{~T} 12$ & $129,472.33$ & $62,978.00$ & 103.29 & $84,036.00$ \\
\hline 3T12 & $125,335.00$ & $66,205.00$ & 83.69 & $87,163.00$ \\
\hline $4 \mathrm{~T} 12$ & $122,786.00$ & $74,085.00$ & 93.66 & $89,082.00$ \\
\hline $1 \mathrm{~T} 13$ & $131,841.67$ & $55,678.56$ & 111.69 & $70,086.00$ \\
\hline $2 \mathrm{~T} 13$ & $135,296.67$ & $61,920.50$ & 99.21 & $78,189.00$ \\
\hline $3 \mathrm{~T} 13$ & $134,040.67$ & $73,435.00$ & 105.58 & $91,242.00$ \\
\hline $4 \mathrm{~T} 13$ & $133,538.33$ & $73,597.00$ & 112.97 & $90,635.00$ \\
\hline $1 \mathrm{~T} 14$ & $134,894.00$ & $57,843.00$ & 90.52 & $75,666.00$ \\
\hline $2 \mathrm{~T} 14$ & $138,569.67$ & $63,726.00$ & 84.60 & $85,074.00$ \\
\hline $3 \mathrm{~T} 14$ & $135,533.00$ & $63,025.00$ & 68.02 & $89,223.00$ \\
\hline
\end{tabular}




\begin{tabular}{lllll}
\hline $4 \mathrm{~T} 14$ & $133,483.33$ & $74,603.00$ & 61.57 & $95,580.00$ \\
$1 \mathrm{~T} 15$ & $136,014.67$ & $59,420.00$ & 46.01 & $75,666.00$ \\
2T15 & $140,180.67$ & $67,230.00$ & 50.62 & $85,074.00$ \\
3T15 & $137,097.00$ & $70,530.00$ & 46.48 & $89,223.00$ \\
$4 \mathrm{~T} 15$ & $134,313.67$ & $79,213.00$ & 37.18 & $95,580.00$ \\
$1 \mathrm{~T} 16$ & $128,460.24$ & $62,744.00$ & 46.50 & $93,700.00$ \\
\hline
\end{tabular}

Fontes: WorldSteel (2015), Vale (2016b), Antaq (2016)

Para esse conjunto de dados foi verificada a variância etrema, normalidade dos dados, multicolinearidade e posteriormente o teste de Regressão Múltipla.

\subsection{Análise de variação extrema}

Primeiramente foi realizada a análise de variação extrema para todos os conjuntos de dados (ver Tabela 1), como pode ser observado no boxplot da Figura 1, visto que é necessária a ausência de outliers para que possa ser realizada Regressão Linear Múltipla.

Figura 1: Boxplot dos conjuntos de dados
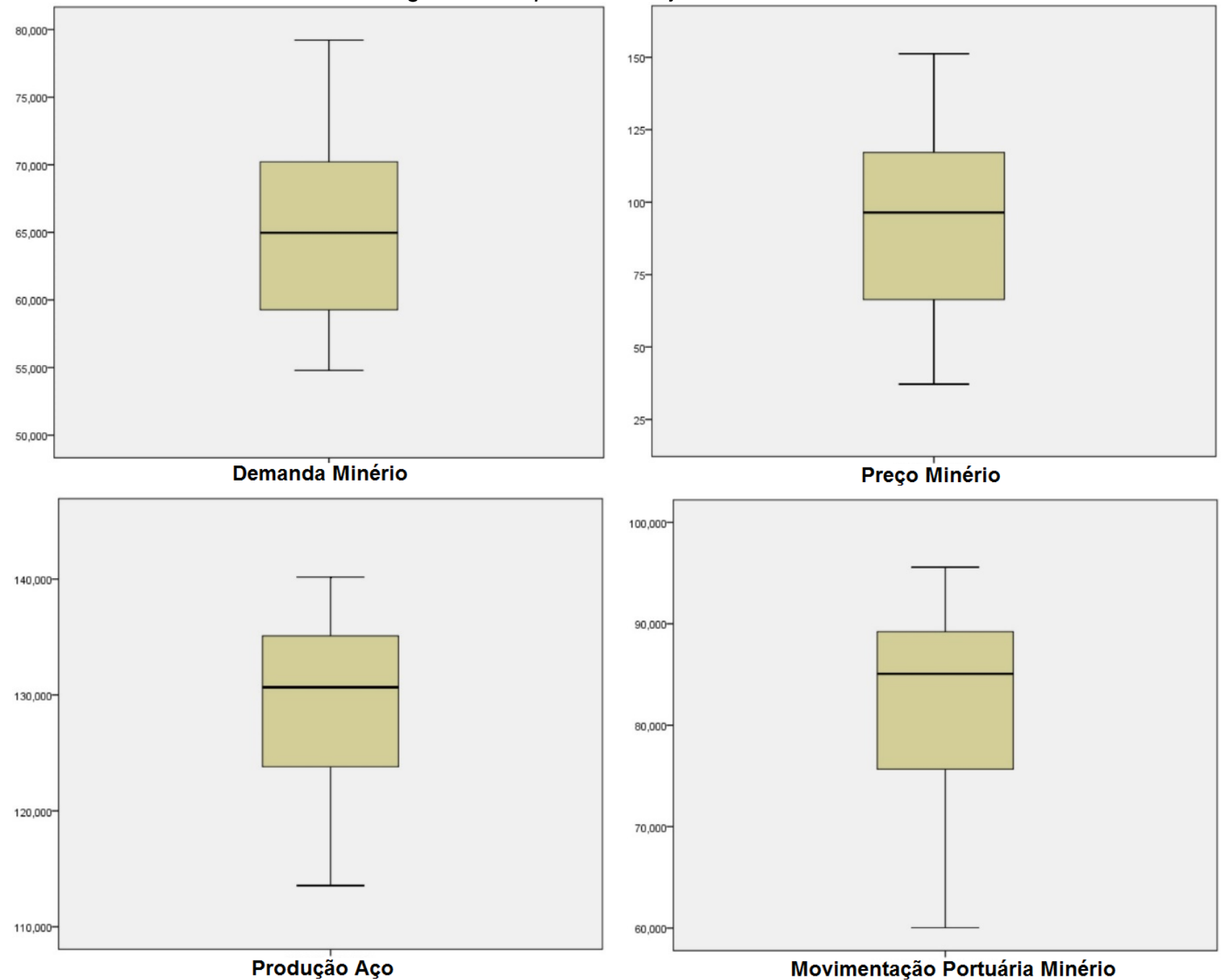

Fonte: Autoria própria (2016)

Pode-se observar que nenhum dos conjuntos de dados apresentam outliers, podendo, assim, ser dada sequência à análise de normalidade. 


\subsection{Análise de normalidade}

Para a análise de normalidade foi utilizado o teste de Shapiro-Wilk, cujos resultados são mostrados na Tabela 2, para cada um dos conjuntos de dados, em função de todos os conjuntos apresentarem 24 elementos cada, sendo o referido teste indicado para amostras menores ou iguais a 30 elementos.

Tabela 2: Teste de normalidade por assimetria e curtose

\begin{tabular}{ccc}
\hline Conjunto de Dados & Assimetria & Curtose \\
\hline Demanda minério de ferro & 0,214 & $-0,896$ \\
Preço de minério de ferro & $-0,151$ & $-0,767$ \\
Produção de aço & $-0,576$ & $-0,749$ \\
Movimentação portuária de minério de ferro & $-0,703$ & 0,045 \\
\hline
\end{tabular}

Fonte: Autoria própria (2016)

De acordo com o teste de Shapiro-Wilk, ao nível de confiança referido, apenas a produção mundial de aço e a movimentação portuária de minério de ferro apresentam distribuição normal, um p-valor maior do que 0,05. De acordo com Dancey e Reidy (2004), contudo, os dados apresentam distribuição normal quando apresentam valores de assimetria e curtose menores do que 1,5 em módulo, sendo o caso de todos os conjuntos de dados analisados. Assim, considerou-se, de acordo com tal análise, que todos os conjuntos de dados são normalmente distribuídos.

\subsection{Análise de correlação}

Uma vez que os conjuntos de dados apresentaram distribuição normal o teste apropriado para a análise de correlação é o de Pearson. A análise de correlação foi conduzido com todos os conjuntos de dados, aos pares, para verificar a tendência de variação conjunta e investigar a presença ou ausência de multicolinearidade, a qual pode muitas vezes interferir nos resultados da regressão linear. Os resultados dos testes de correlação, aos pares, são apresentados na Tabela 3.

Tabela 3: Correlação dos conjuntos de dados aos pares

\begin{tabular}{ccccc}
\hline & $\begin{array}{c}\text { Demanda } \\
\text { minério de ferro }\end{array}$ & $\begin{array}{c}\text { Preço de } \\
\text { minério de } \\
\text { ferro }\end{array}$ & $\begin{array}{c}\text { Produção } \\
\text { de aço }\end{array}$ & $\begin{array}{c}\text { Movimentação } \\
\text { portuária de } \\
\text { minério de ferro }\end{array}$ \\
\hline $\begin{array}{c}\text { Demanda minério de Ferro } \\
\text { Preço de minério de Ferro }\end{array}$ & 0.82 & 0.082 & -0.178 & $0.885^{*}$ \\
$\begin{array}{c}\text { Produção de aço } \\
\text { Movimentação portuária de } \\
\text { minério de ferro }\end{array}$ & -0.178 & 1 & $-0.485^{\star}$ & 0.299 \\
\hline
\end{tabular}

* Correlação é significativa ao nível de 0.05 (bilateral)

Fonte: Autoria própria (2016) 
A Figura 2 mostra graficamente o comportamento dos conjuntos de dados.

Figura 2: Gráficos de correlações entre os conjuntos de dados (par a par)

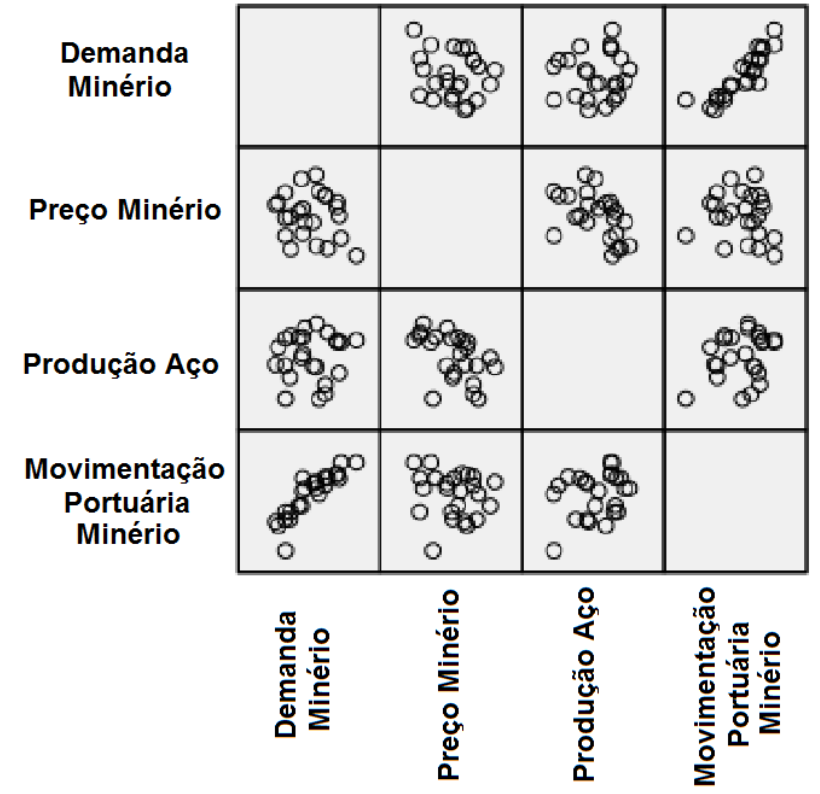

Fonte: Autoria própria (2016)

A análise de correlação é necessária para avaliar se há multicolinearidade (coeficiente de correlação maior ou igual a 0,9 ) entre as variáveis independentes, neste caso o preço do minério de ferro, a produção de aço e a movimentação portuária de minério de ferro. Em caso de multicolinearidade, as variáveis utilizadas explicam a mesma tendência, podendo ser combinadas ou descartadas para a análise de regressão (VALENTE et al., 2011). Petrini et al. (2012) colocam que a multicolinearidade pode também ser observada quando o modelo apresenta termos em excesso.

Neste caso, observa-se que nenhum par de variáveis independentes apresenta coeficiente de correlação maior ou igual a 0,9 , portanto, não há presença de multicolinearidade. Ademais, apenas as correlações entre "preço de minério de ferro" e "produção de aço" e "demanda de minério de ferro" e "movimentação portuária" são significativas a um $p$-valor de 0,05 .

\subsection{Análise de Regressão Linear Múltipla}

Como objetivo principal do presente estudo tem-se a condução da análise de regressão linear múltipla para descoberta da equação de demanda para o minério de ferro. Definiu-se as variáveis dependentes e independentes. Foram definidas como variáveis independentes (variáveis preditoras) a produção de aço, o preço do minério de ferro e a movimentação portuária de minério de ferro, as quais logicamente podem causar influência na variável dependente, no caso a demanda de minério de ferro. $O$ resumo da análise é apresentado na Tabela 4.

Tabela 4: Resumo da Análise de Regressão Linear Múltipla

\begin{tabular}{cccc}
\hline $\mathbf{R}$ & $\mathbf{R}^{\mathbf{2}}$ & $\mathbf{R}^{\mathbf{2}}$ ajustado & Erro padrão da estimativa \\
\hline $0,921^{\mathrm{a}}$ & 0,848 & 0,826 & $2.822,69$ \\
\hline
\end{tabular}

apreditores: constante, produção de aço, movimentação portuária e preço do minério Fonte: Autoria própria (2016) 
Tendo em mãos os resultados das análises pré-condicionais e definidas as variáveis independentes e a variável dependente foi então conduzida à análise de regressão linear múltipla ao nível de confiança de $95 \%$.

Foi obtido um $\mathrm{R}^{2}$ ajustado de 0,826 o que indica que os elementos preditores forneceram um modelo com ajuste de $82,6 \%$. Valor considerado moderadamente alto por (DANCEY; REIDY, 2004). Valores menores, em torno de $60 \%$ podem ainda ser considerados razoáveis (PITOMBO; COSTA, 2015), desde que apresentem significância estatística (GEA-IZQUIERDO, 2012). Ainda, o teste de análise de variância (ANOVA) indicou que o modelo é estatisticamente significativo ao nível de confiança de 95\%, mostrando que o pressuposto de linearidade não foi ferido.

Cabe-se, ademais, atentar para a necessidade de considerar a Constante encontrada para a equação de regressão também com preditora, uma vez que a mesma tem papel fundamental na previsão da variável dependente (demanda de minério de ferro), principalmente em função da mesma considerar um $p$-valor de 0,05.

A Tabela 5, a seguir, mostra os coeficientes para os preditores na previsão da variável dependente ao nível de significância obtido.

Tabela 5: Coeficientes dos Elementos Preditores

\begin{tabular}{|c|c|c|}
\hline Variável & $\begin{array}{c}\text { Coeficiente } \\
\text { Não-Padronizado }\end{array}$ & $\begin{array}{c}\text { Coeficiente } \\
\text { Padronizado }\end{array}$ \\
\hline Constante $^{\star}$ & $42.518,029$ & ( \\
\hline Preço minério & $-41,094$ & $-0,193$ \\
\hline Movimentação portuária minério* & 0,713 & 0,947 \\
\hline Produção aço* & $-0,249$ & $-0,295$ \\
\hline
\end{tabular}

Apenas o coeficiente atribuído à variável preço do minério de ferro é não significativo ao nível de confiança de $95 \%$. Os demais coeficientes (movimentação portuária de minério de ferro, a produção mundial de aço e a constante atribuída à equação de regressão) são estatisticamente significativos ao nível de confiança referido.

Os coeficientes não-padronizados são os coeficientes utilizados para construir a equação de demanda a partir do teste de regressão linear múltipla. Os coeficientes padronizados indicam a proporção da variável dependente que a variável preditora explica. Assim, o preço do minério de ferro explica $19 \%$ da variação inversa da demanda de minério de ferro, a movimentação portuária de minério de ferro explica $95 \%$ da demanda de minério de ferro e a produção mundial de aço explica $29 \%$ da variação inversa da demanda de minério de ferro.

Com isso obtém-se a seguinte equação de regressão (Eq.1):

$$
\text { D_Min }=42.518,03-41,09 \times \text { Pre_Min }+0,71 \times \text { Mov_Port_Min }-0,25 \times \text { Prod_Aco (Eq.1) }
$$

Onde:

D_Min: demanda de minério de ferro

Pre_Min: preço do minério de ferro

Mov_Port_Min: movimentação portuária de minério de ferro

Prod_Aco: produção mundial de aço 


\subsubsection{Corroboração dos dados do modelo}

Para testar a validade dos resultados obtidos é necessário comparar os dados resultantes da equação gerada e dados reais determinando o erro de previsão para a demanda de minério de ferro. Para tanto, a Tabela 6 mostra os dados reais de produção da empresa Vale S.A. e a previsão gerada pelo modelo proposto seguido do erro de previsão para o respectivo período. A determinação do erro de previsão foi obtida por meio da (Eq.2) (BALLOU, 2001):

$$
E_{t}=\frac{\left|D_{t}-F_{t}\right|}{D_{t}}
$$

Onde,

$E_{t:}$ erro relativo de previsão à demanda real no período $t$

$D_{t}$ : demanda real no período $t$

$F_{t}$ : previsão de demanda no período $t$

Tabela 6: Coeficientes dos Elementos Preditores

\begin{tabular}{lllrc}
\hline Trimestre & $\begin{array}{c}\text { Minério de ferroa } \\
\text { (mil ton.m) }\end{array}$ & $\begin{array}{c}\text { Previsão } \\
\text { (mil ton.m) }\end{array}$ & $\begin{array}{c}\text { Demanda - Previsão } \\
\text { (mil ton.m) }\end{array}$ & $\begin{array}{c}\text { Erro relativo de } \\
\text { previsão } \\
\text { (\%) }\end{array}$ \\
\hline 1T10 & $57,875.00$ & $54,357.35$ & $3,517,65^{\mathrm{e}}$ & 6.08 \\
2T10 & $59,124.00$ & $60,320.81$ & $-1,196,81$ & 2.02 \\
3T10 & $68,043.00$ & $68,046.45$ & $-3,45$ & 0.01 \\
4T10 & $69,860.00$ & $70,456.43$ & $-596,43$ & 0.85 \\
1T11 & $57,745.00$ & $57,809.18$ & $-64,18$ & 0.11 \\
2T11 & $62,644.00$ & $60,272.46$ & $2,371,54$ & 3.79 \\
3T11 & $67,007.81$ & $67,839.91$ & $-832,11$ & 1.24 \\
4T11 & $69,890.26$ & $71,900.35$ & $-2,010,09$ & 2.88 \\
1T12 & $54,793.00$ & $57,793.27$ & $-3,000,27 \mathrm{e}$ & 5.48 \\
2T12 & $62,978.00$ & $65,952.49$ & $-2,974,49 \mathrm{e}$ & 4.72 \\
3T12 & $66,205.00$ & $70,017.49$ & $-3,812,49 \mathrm{e}$ & 5.76 \\
4T12 & $74,085.00$ & $71,610.81$ & $2,474,19$ & 3.34 \\
1T13 & $55,678.56$ & $55,070.95$ & 607,61 & 1.09 \\
2T13 & $61,920.50$ & $60,501.07$ & $1,419,43$ & 2.29 \\
3T13 & $73,435.00$ & $69,858.89$ & $3,576,11$ & 4.87 \\
4T13 & $73,597.00$ & $69,247.49$ & $4,349,51^{\mathrm{e}}$ & 5.91 \\
1T14 & $57,843.00$ & $59,159.42$ & $-1,316,42^{\mathrm{e}}$ & 2.28 \\
2T14 & $63,726.00$ & $65,195.53$ & $-1,469,53$ & 2.31 \\
3T14 & $63,025.00$ & $69,591.07$ & $-6,566,07 \mathrm{e}$ & 10.42 \\
4T14 & $74,603.00$ & $74,899.23$ & $-296,23$ & 0.40 \\
1T15 & $59,420.00$ & $60,709.50$ & $-1,289,50$ & 2.17 \\
2T15 & $67,230.00$ & $66,190.63$ & $1,039,37$ & 1.55 \\
3T15 & $70,530.00$ & $70,086.83$ & 443,17 & 0.63 \\
4T15 & $79,213.00$ & $75,694.59$ & $3,518,41^{\mathrm{e}}$ & 4.44 \\
& Erro relativo médio de 24 trimestres & & $\mathbf{3 , 1 1}$ \\
\hline
\end{tabular}

e módulo do desvio excede o erro padrão

Fonte: Vale (2016b) 
É possível perceber que a previsão se mostra válida apresentando uma flutuação aceitável ao longo dos 24 trimestres analisados, com um erro relativo médio ao longo dos 24 trimestres analisados de somente $3,11 \%$. Os dados de demanda real e de previsão apresentam comportamento bastante parecido, que pode ser melhor observado por meio da Figura 3.

Figura 3 - Demanda Real versus Previsão

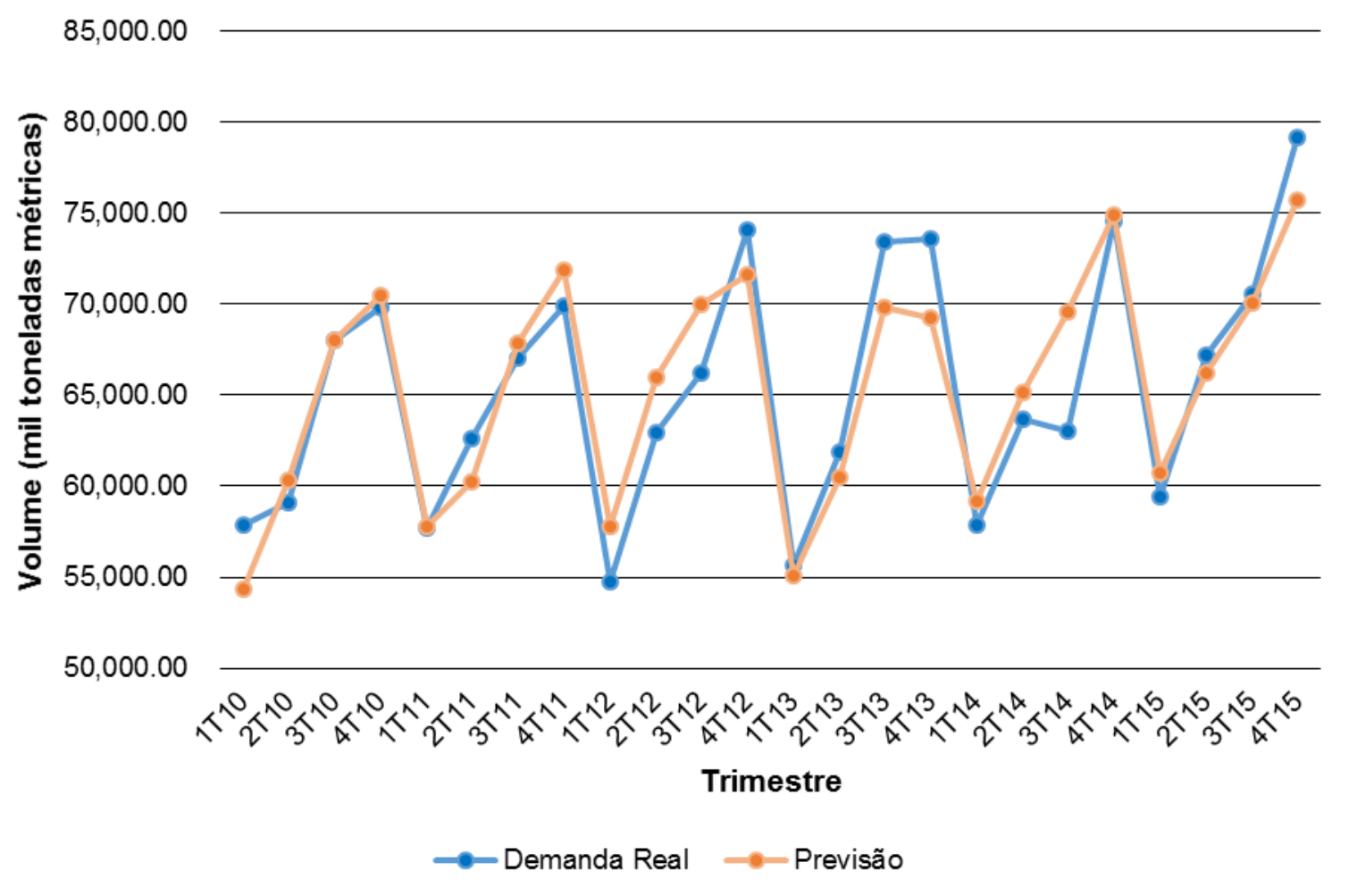

Fonte: Autoria própria (2016)

As maiores discrepâncias podem ser observadas nos trimestres 3T13, 4T13 e $3 \mathrm{~T} 14$, com $4,87 \%, 5,91 \%$ e $10,42 \%$ de erro relativo à demanda real, respectivamente. Tais valores são variações extremas e como se trata de uma organização privada com interesses particulares é necessário avaliar em conjunto com a mesma qual seria a margem de erro aceitável para a análise proposta. Todavia, outros autores (BOUZADA; SALIBY, 2009) também realizando análises de previsão de demanda pelo método de regressão linear múltipla encontraram erros de $11 \%$ considerando valores razoáveis, comparando ainda a outros métodos, os quais apresentaram erros maiores.

Também, apenas 8 dos 24 trimestres excedem o erro padrão (ver Tabela 4) para a previsão. Os demais apresentam desvios deveras baixos chegando até mesmo a apresentar uma diferença de somente 3,45 mil toneladas métricas (3T10) em relação à demanda real, o que representa um erro relativo de $0,01 \%$.

\section{Conclusões}

O presente trabalho teve como objetivo realizar a previsão de demanda do minério de ferro da empresa Vale S.A. no período de 2010 a 2015. Dentre os vários métodos disponíveis para previsão de demanda utilizou-se a regressão linear múltipla devido à observação de variação conjunta das variáveis preditivas produção mundial de aço, preço do minério de ferro e movimentação portuária minério de ferro. Por meio da referida análise obteve-se a seguinte equação para previsão da demanda de minério de ferro: 


$$
\text { D_Min }=42.518,03-41,09 \times \text { Pre_Min + 0,71 } \times \text { Mov_Port_Min }-0,25 \times \text { Prod_Aco }
$$

Obteve-se um $\mathrm{R}^{2}$ ajustado maior do que $82 \%$ e a partir da utilização da equação acima, o erro relativo médio de previsão observado foi de $3,11 \%$, devido à flutuação inerente ao mercado e às incertezas embarcadas em qualquer sistema estatístico.

Outrossim, sugere-se que em estudos futuros seja discutido o comportamento da série histórica de demanda de minério de ferro da empresa Vale S.A. para a aplicação de diferentes métodos de previsão de demanda e a avaliação das incertezas decorrentes do método utilizado para determinação do erro de previsão e acuracidade daquele, pois os erros são uma forma de escolha do modelo de previsão.

\section{Referências}

ANTAQ - AGÊNCIA NACIONAL DE TRANSPORTEA AQUAVIÁRIOS. Boletim Informativo Portuário. Disponível em: <http://www.antaq.gov.br/portal/pdf/BoletimPortuario/BoletimPortuarioPrimeiroTrimestre20 15.pdf http://www.antaq.gov.br/anuario/>. Acesso em: 23 Mai. 2016.

BALLOU, R. H. Gerenciamento da cadeia de suprimentos: planejamento, organização e logística empresarial. 4. ed. Porto alegre: Bookman, 2001.

BOUZADA, M. A. C.; SALIBY, E. Prevendo a demanda de ligações em um call center por meio de um modelo de regressão múltipla. Gestão e Produção, São Carlos, v. 16, n. 3, p. 382-397, jul./sep. 2009.

CARVALHO, P. S. et al. Minério de Ferro. BNDES Setorial, Rio de Janeiro, v. 39, p. 197$234.2013 . \quad$ Disponível em: <http://www.bndes.gov.br/SiteBNDES/export/sites/default/bndes_pt/Galerias/Arquivos/con hecimento/bnset/set3906.pdf>. Acesso em: 15 de Jun. 2016.

DANCEY, C. P.; REIDY, J. Estatística sem matemática para psicologia: usando SPSS para windows. 3. ed. Porto Alegre: Pearson, 2004.

GEA-IZQUIERDO, E. Multiple regression as a preventive tool for determining the risk of Legionella spp. Universitas Scientiarum, Bogota, v. 17, n. 1, p. 64-71, jan/abr 2012.

LAUINGER, D. et al. A linear programming approach to the optimization of residential energy systems. Journal of Energy Storage, Aachen, v. 7, n. 1, p. 24-37, ago. 2016.

MA, W.; ZHU, X.; WANG, M. Forecasting iron ore import and consumption of China using grey model optimized by particle swarm optimization algorithm. Resources Policy, Inglaterra, v. 38, n. 4, p. 613-620, dez. 2013.

MAKRIDAKIS, S.; WHEELWRIGHT, S. C.; HYNDMAN, R. J. Forecasting: methods and applications. 3. ed. United States of America: John Wiley and Sons, 1998.

MANCUZO, F. Análise e Previsão de Demanda: Estudo de Caso em uma Empresa Distribuidora de Rolamentos. 2003. 142 f. Dissertação (Mestrado em Engenharia de Produção) Pós-Graduação em Engenharia de Produção, Universidade Federal do Rio Grande do Sul, Porto Alegre.

MARTINS, P. G.; LAUGENI, F. P. Administração da produção. 2. ed. São Paulo: 
Saraiva, 2005.

IBRAM (INSTITUTO BRASILEIRO DE MINERAÇÃO) (Minas Gerais). Informações e Análises da Economia Mineral Brasileira. 7. ed. Belo Horizonte: São Miguel, 2012. 68 p. Disponível em: <http://www.ibram.org.br/sites/1300/1382/00002806.pdf>. Acesso em: 10 Dez. 2016.

MIRANDA, R. G. et al. Método estruturado para o processo de planejamento da demanda nas organizações. Revista ADMpg Gestão Estratégica, Ponta Grossa, v. 4, n. 1, p.4553, mar./jul. 2011.

PELLEGRINI, F. R.; FOGLIATTO, F. S. Passos para implantação de sistemas de previsão de demanda: técnicas e estudo de caso. Produção, São Paulo, v. 11, n. 1, p.43-64, jan./jun. 2001.

PETRINI, J. et al. Degree of multicollinearity and variables involved in linear dependence in additive-dominant models. Pesquisa Agropecuária Brasileira, Brasília, v. 47, n. 12, p. 1743-1750, dez. 2012.

PITOMBO, C. S., COSTA, A. S. G. Aplicação conjunta de modelos não paramétricos e paramétricos para previsão de escolha modal. Journal of Transport Literature, Manaus, v. 9, n. 1, p. 30-34, jan. 2015.

SHARMA, S. K.; SHARMA, G. K. Demand forecasting techniques vis-à-vis demand forecast for lead. Procedia Earth and Planetary Science, Newcastle, v. 11, p. 418-424, dez. 2015.

SLACK, N. et al. Administração da Produção. 2. ed. São Paulo: Atlas, 2007.

SOUSA, D. C. G. et al. PCP e previsão da demanda, 2014. Disponível em: <http://pt.slideshare.net/IngridianeAlbuquerqu/pcp-e-previso-da-demanda>. Acesso em: 21 maio. 2016.

VALE. Mineração. 2016a. Disponível em: <http://www.vale.com/brasil/PT/business/mining/Paginas/default.aspx>. Acesso em: 15 de jun. 2016.

VALE. Resultados Trimestrais de 2010 a 2015. Disponível em: < http://www.vale.com/brasil/pt/investors/information-market/quarterlyresults/paginas/default.aspx>. Acesso em: 23 de maio 2016b.

VALENTE, M. D. R. et al. Modelo de predição para o volume total de quaruba (vochysia inundata ducke) via análise de fatores e regressão. Revista Árvore, Viçosa, v. 35, n. 2, p. 307-317, mar./abr. 2011.

WANG, J. et al. China's natural gas production and consumption analysis based on the multicycle Hubbert model and rolling Grey model. Renewable and Sustainable Energy Reviews, Golden, v. 53, n. 2, p. 1149-1167, jan. 2015. 
WORLDSTEEL. Steel Statistical Yearbook 2010 to 2015. Bruxelas: Worldsteel, 2015.

XUAN, Y.; YUE, Q. Forecast of steel demand and the availability of depreciated steel scrap in China. Resources, Conservation and Recycling, Holanda, v. 109, n. 1, p. 1-12, may. 2016. 